\title{
When is a parasite not a parasite? Effects of larval tick burdens on white-footed mouse survival
}

\author{
Michelle H. Hersh, ${ }^{1,2,4}$ Shannon L. Ladeau, ${ }^{1}$ M. Andrea Previtali, ${ }^{3}$ and Richard S. Ostfeld ${ }^{1}$ \\ ${ }^{1}$ Cary Institute of Ecosystem Studies, Millbrook, New York 12545 USA \\ ${ }^{2}$ Program in Biology, Bard College, Annandale-on-Hudson, New York 12504 USA \\ ${ }^{3}$ Departamento de Ciencias Naturales, Facultad de Humanidades y Ciencias, Universidad Nacional del Litoral \\ Consejo Nacional de Investigaciones Cientificas y Técnicas (CONICET), Santa Fe 3000 Argentina
}

\begin{abstract}
Many animal species can carry considerable burdens of ectoparasites or parasites living on the outside of a host's body. Ectoparasite infestation can decrease host survival, but the magnitude and even direction of survival effects can vary depending on the type of ectoparasite and the nature and duration of the association. When ectoparasites also serve as vectors of pathogens, the effects of ectoparasite infestation on host survival have the potential to alter disease dynamics by regulating host populations and stabilizing transmission. We quantified the impact of larval Ixodes scapularis tick burdens on both within-season and overwinter survival of white-footed mice (Peromyscus leucopus) using a hierarchical Bayesian capture-mark-recapture model. I. scapularis and P. leucopus are, respectively, vectors and competent reservoirs for the causative agents of Lyme disease, anaplasmosis, and babesiosis. Using a data set of 5587 individual mouse capture histories over sixteen years, we found little evidence for any effect of tick burdens on either within-season or overwinter mouse survival probabilities. In male mice, tick burdens were positively correlated with within-season survival probabilities. Mean maximum tick burdens were also positively correlated with population rates of change during the concurrent breeding season. The apparent indifference of mice to high tick burdens may contribute to their effectiveness as reservoir hosts for several human zoonotic pathogens.
\end{abstract}

Key words: Bayesian analysis; capture-mark-recapture model; ectoparasites; Ixodes scapularis; Peromyscus leucopus; state-space model; survival.

\section{INTRODUCTION}

Parasites, by definition, negatively impact hosts. The consequences of these negative impacts on host-parasite dynamics depend to a great extent on whether the cost to an individual host increases as the burden of parasites on that host increases. Macroparasites can regulate host populations in a density-dependent manner if hosts incur greater fitness costs as parasite burdens increase (Anderson and May 1978). This could lead to a negative feedback between host populations and parasite populations, particularly if overall parasite abundance increases with overall host abundance. In contrast, if the fitness effects of the parasite on the host are not correlated with parasite density, negative feedbacks would be less likely, and therefore, there would be less stability in the parasite-host relationship.

The effects of parasites on host fitness manifest themselves through their impacts on host health. We focused on ectoparasites, a taxonomically diverse group

Manuscript received 12 December 2012; revised 23 September 2013; accepted 30 September 2013; final version received 7 October 2013. Corresponding Editor: D. R. Strong.

${ }^{4}$ Present address: Department of Biology, Sarah Lawrence College, 1 Mead Way, Bronxville, New York 10708 USA. E-mail:mhersh@sarahlawrence.edu of parasites that live exclusively on the outside of a host's body and that associate with their hosts for varying lengths of time. Some ectoparasites have been shown to affect host body condition and physiology (Hawlena et al. 2006b, Lourenco and Palmeirim 2007, Heylen and Matthysen 2008), reproduction (Moller 1993, Neuhaus 2003, Fitze et al. 2004a, b, Hillegass et al. 2010), and aspects of host behavior including grooming (Hillegass et al. 2010), dispersal (Brown and Brown 1992), and foraging (Raveh et al. 2011). Such impacts of ectoparasite infestation, both individually and in combination, could, in theory, influence host survival and population dynamics depending on the taxonomic identities of the host and parasite, along with the duration of the infestation.

Effects of ectoparasitism on animal survival are variable. In some cases, ectoparasites decrease survival at the scale of the whole population (Brown et al. 1995, Brown and Brown 2004, Krkosek et al. 2007, Devevey and Christe 2009), but effects are not uniform across individuals within a population. In several animal populations, including cliff swallows (Brown and Brown 2004), roseate terns (Monticelli et al. 2008), and gerbils (Hawlena et al. 2006a), negative effects on survival were more pronounced in juveniles than adults. Negative impacts of ectoparasites on nestling growth and survival 
have been observed in multiple bird species (Clayton and Tompkins 1995, Merino and Potti 1995, Ramos et al. 2001, Antoniazzi et al. 2011). Although an experimental study of tick infestation in birds found greater blood depletion in males than females (Heylen and Matthysen 2008), other avian studies have found no differences in parasite effects on survival between the sexes (Brown and Brown 2004). Environmental factors, such as water temperature with fish, can also alter the severity of any negative ectoparasite effects (Cardon et al. 2011) or the intensity of infection (Antoniazzi et al. 2011). Yet in some cases, organisms classified as ectoparasites have had no detectable influence (Lee and Clayton 1995, Gauthier-Clerc et al. 2003) or even a positive relationship with survival (Brown et al. 2006). This variation in the impact of ectoparasites on survival indicates that ectoparasites may not always have negative effects on all individuals in a population.

In addition, ectoparasite burdens can vary considerably between individuals, with high levels of aggregation at the individual level (Anderson and May 1978, Brunner and Ostfeld 2008, Devevey and Brisson 2012). This variation in ectoparasite loads could be the basis for differential effects on survival between individuals. Some patterns in variation among individuals can be due to individual characteristics or traits. For example, higher ectoparasite burdens in males are frequently documented (Perez-Orella and Schulte-Hostedde 2005, Gorrell and Schulte-Hostedde 2008, Devevey and Brisson 2012), but multiple exceptions to this general trend exist (Krasnov et al. 2005, Christe et al. 2007, Kiffner et al. 2011) or may be attributable to body size differences between the sexes (Harrison et al. 2010). Ectoparasite loads can vary with age (Cardon et al. 2011) or space use (Boyer et al. 2010, but see also Devevey and Brisson 2012). Individual differences in ectoparasite burdens may also be a function of chance alone, such as having a home range in a particularly ectoparasite-rich locality (Calabrese et al. 2011). Regardless of the mechanism driving variation in ectoparasite burdens, individual differences in loads could form the basis of differential effects on survival.

We examined the impacts of larval Ixodes scapularis (blacklegged) ticks on the survival of white-footed mice (Peromyscus leucopus). We focused on the effects of blacklegged tick parasitism on white-footed mouse survival because of the importance of this vector and host. Blacklegged ticks are generalist ectoparasites that serve as the vector of multiple disease agents in eastern and central North America, including the causal agents of Lyme disease (Borrelia burgdorferi), human granulocytic anaplasmosis (Anaplasma phagocytophilum), and human babesiosis (Babesia microti; LoGiudice et al. 2003, Hersh et al. 2012, Keesing et al. 2012). Whitefooted mice are one of the most competent reservoir hosts for all three of these pathogens (LoGiudice et al. 2003, Hersh et al. 2012, Keesing et al. 2012), and the abundance of B. burgdorferi-infected ticks is correlated with abundance of mice (Ostfeld et al. 2006). These mice can carry large larval tick burdens (as many as 270 ticks/ mouse in this study) and appear to be relatively tolerant of tick parasitism, allowing approximately half of the larval ticks they encounter to feed successfully (Keesing et al. 2009). Larval ticks are not infected with $B$. burgdorferi, A. phagocytophilum, or B. microti, as vertical transmission of these pathogens is nonexistent or rare (Civitello et al. 2010), so any negative effects of larval ticks on mice would likely be due to tick feeding alone rather than pathogen transmission. When an ectoparasite also acts as a vector and the host as a reservoir for a pathogen, ectoparasite-induced changes in host demography could translate into altered disease dynamics.

If blacklegged ticks have a strong negative impact on white-footed mouse health, then we expect to see a reduction in mouse survival probabilities as tick burdens increase. Such reduced survival should lead to negative correlations between mean tick burden and population rate of change. On the other hand, if ticks have little to no negative impact on host health, survival probabilities would be independent of variation in tick burden, heavily parasitized individuals would survive as long as unparasitized ones, and population rate of change should not decline with increasing tick burden. This has the potential to increase disease risk by increasing opportunities for ticks to feed on the hosts most permissive of feeding (Keesing et al. 2009), potentially resulting in higher overall tick densities.

To determine the effects of larval tick burden on survival of white-footed mice, we employed sixteen years of capture-mark-recapture data and tick counts at each capture of over 5500 individual mice. We investigated tick effects on both within-season and overwinter survival and considered potential sex differences given that male white-footed mice are known to have larger larval tick burdens than females (Brunner and Ostfeld 2008, Devevey and Brisson 2012). To determine if the effects of tick burdens were altered by stressors on resource availability, we ran the model on subsets of data representing variation in the effects of acorn production by the regionally dominant oaks (genus Quercus), given that overwinter survival and summer abundance of mice are correlated with acorn abundance the prior fall (Ostfeld et al. 1996, 2006, Jones et al. 1998), and mouse population density, as rodent survival rates are sometimes inversely correlated with population density (e.g., Turchin 2003). We predicted that if negative effects of larval burdens on survival did occur, they would be more pronounced during stressful periods of limited resource availability (e.g., due to low acorn availability or high mouse population density). We estimated survival probabilities using a state-space model implemented in a hierarchical Bayesian framework (Clark et al. 2005, Gimenez et al. 2007, Royle 2008), so that we could evaluate the effects of tick burden on survival, while accounting for both individual 
and annual variation in mouse survival and allowing for observation error. We also examined the relationship between average tick burdens and population rates of change during the breeding season. Ultimately, our goal was to expand our understanding of the role of mice in the dynamics of tick-borne diseases via the effects of tick vectors on mouse survival.

\section{Materials and Methods}

\section{Field methods}

Field data were collected from a long-term capturemark-recapture study conducted from 1995 to 2011 on six 2.25-ha trapping plots in Millbrook, New York, USA (Ostfeld et al. 2006, Brunner and Ostfeld 2008). On each plot, an $11 \times 11$ point grid of Sherman live traps (H. B. Sherman Traps, Tallahassee, Florida, USA) was established, with $15 \mathrm{~m}$ between trap stations and two traps per station, for a total of 242 traps per grid. Trapping was conducted for two consecutive nights every three to four weeks, generally from May to November of each year. Traps were baited with crimped oats (sunflower seeds and cotton batting were added during cold weather), set at 16:00 and checked between 08:00 and about 12:00 the following morning. Small mammals were marked with individually numbered metal ear tags and released after handling at the point of capture. Data on age, sex, reproductive status, body mass, and trap station were recorded on each capture. Ectoparasite burden data was recorded on the first capture in each trapping session and consisted of carefully inspecting the head (including ear pinnae) and neck of each mouse while counting all attached ticks of each life stage. A strong relationship has been observed between these field counts and whole-body burdens and was determined by holding mice in wiremesh cages over collecting pans for $>3 \mathrm{~d}$ (the duration of larval feeding; $R^{2}=0.79$ [Brunner and Ostfeld 2008]). Protocols for animal handling were approved annually by an Institutional Animal Care and Use Committee. In six years $(1995,1997,1998,2008,2009$, and 2010), only data from three of six grids could be used given experimental manipulations on the other three grids, including acorn supplementation and mouse or chipmunk removal (Ostfeld 2011), that could affect estimates of survival. Summarized trapping data are included in Appendix A. Annual acorn production was measured using seed baskets as described in Ostfeld et al. (2006). White-footed mouse population density was estimated as the minimum number alive (MNA) or using a JollySeber open population model (J-S) as described in Ostfeld et al. (2006).

\section{Statistical modeling}

White-footed mouse survival was estimated using a state-space formulation (Clark et al. 2005, Gimenez et al. 2007, Royle 2008) of the Cormack-Jolly-Seber model (Cormack 1964, Jolly 1965, Seber 1965), which estimates animal survival in an open population from capture- mark-recapture data. This model was implemented in a hierarchical Bayesian framework and has two main components: a process model that describes the unobserved or partially observed process of interest, and an observation model that describes our ability to measure or sample this process. The data are a series of observations $\left(\mathrm{Y}_{1} \ldots \mathrm{Y}_{T}\right)$ of whether or not animal $i$ is captured (1, captured; 0 , not captured) from times 1 through $T$. These observations are dependent on the actual state of the animal (1, alive; 0 , dead) at each time step $\left(\mathrm{X}_{1} \ldots \mathrm{X}_{T}\right)$, which we cannot directly observe for all individuals

$$
\begin{gathered}
Y_{i, t} \mid X_{i, t} \sim \operatorname{Bernoulli}\left(X_{i, t} p\right) \\
X_{i, t+1} \mid X_{i, t} \sim \operatorname{Bernoulli}\left(X_{i, t} \Phi_{i, t}\right) .
\end{gathered}
$$

Thus, we modeled both the observation (Eq. 1) and the process (Eq. 2) of survival, estimating the probability of observing an individual mouse (capture probability, $p$ ) in Eq. 1 and the probability that a given individual survives (survival probability, $\Phi$ ) in Eq. 2.

Survival probability was modeled as a logistic generalized linear mixed model with a logit link

$$
\operatorname{logit} \Phi_{i, t}=\mu_{t}+\beta_{t} x_{i}+\alpha_{y(t)}+\gamma_{i}
$$

The process model includes parameter estimate values for the intercept $\left(\mu_{t}\right)$, the effect of tick burden $\left(\beta_{t}\right)$, where $x_{i}$ is the normalized maximum larval tick burden, and random effect estimates for each year $\left(\alpha_{\mathrm{y}(t)}\right)$ and individual $\left(\gamma_{i}\right)$, modeled as a random effect with mean zero and variance $\sigma_{\mathrm{a}}^{2}\left(\alpha\right.$, year) and $\sigma_{\mathrm{g}}^{2}(\gamma$, individual), respectively. The individual random effects account for the nonindependent temporal structure of repeated measures for an individual. Subscript $t$ indicates time steps (intervals between trapping sessions), while subscript $y(t)$ indicates trap sessions in each sampling year.

For each individual mouse, capture histories included five trapping sessions (encompassing four intervals). For this model, the first trapping session included for each individual $\left(t_{1}\right)$ was by definition that which took place during the onset of larval peak determined for each year. Based on data from regular sampling conducted between 1992 and 1995 of immature (larval and nymphal) ticks seeking a host and attached to hosts, we observed that host-seeking and host-feeding activity of larvae were low until mid July, reached a peak between late July and late August, and declined to low levels by late September (see Brunner and Ostfeld 2008). Consequently, we defined larval peak as the two trapping sessions with highest mean tick burdens (late July-mid August), which typically began in week 31 or 32 of a calendar year. The first trapping session was followed by three additional sessions that year, approximately three weeks apart $\left(t_{2-4}\right)$. The fifth trapping session $\left(t_{5}\right)$ designates whether or not an individual was captured during the first trapping session of the following calendar year (interval occurring over the 
winter). Of individuals that were captured in two consecutive years, $82.5 \%$ were captured during the first trapping session of the second calendar year (typically in April or May). Although trapping occurred prior to $t_{1}$ in all years, we only used samples during and after the larval peak in estimating survival to reduce the effects of mouse phenotype (e.g., home range size, behavior) during the pre-peak period on estimates of survival and capture probability.

We interpret the first three intervals as within-season survival or $\Phi_{\mathrm{w}}$ and the final interval as overwinter survival or $\Phi_{\mathrm{o}}$. Eq. 3 was fit to both within-season and overwinter survival data, such that parameters for within-season (first three intervals, $\mu_{\mathrm{w}}, \alpha_{\mathrm{w}}$, and $\beta_{\mathrm{w}}$ ) and overwinter (fourth interval, $\mu_{\mathrm{o}}, \alpha_{\mathrm{o}}$, and $\beta_{\mathrm{o}}$ ) effects were estimated separately. Tick burdens $\left(x_{i}\right)$ were defined as the maximum number of ticks counted from individual $i$ on any single occasion during larval peak (either trapping sessions $t_{1}$ or $t_{2}$ ). Only individuals captured during larval peak were included in the model. If an individual was captured during larval peak in two consecutive years $(0.03 \%$ of all individuals), only the first capture history was included in the model to maintain independence of individuals.

Capture probability, $p$, was assumed to be uniform across all time steps given the high capture probabilities of white-footed mice in this system (Ostfeld et al. 1997, Jones et al. 1998, Schmidt et al. 2001). We confirmed the validity of this simplifying assumption by directly estimating capture probability from a subset of individuals who survived one winter for the nine years in which more than 10 individuals survived the winter $(n=305$ mice). Using strings of three consecutive trapping occasions, we identified individuals captured in the first and third trapping sessions and estimated capture probability based on the percentage of those individuals also captured in the middle session. The resulting mean capture probabilities were as follows (mean \pm SD): within-season trapping sessions $t_{2}, p=0.869 \pm 0.120 ; t_{3}$, $p=0.915 \pm 0.066$; and $t_{4}, p=0.755 \pm 0.115$; and overwinter trapping session $t_{5}, p=0.916 \pm 0.078$. Moreover, a review of variation on capture probabilities by Hammond and Anthony (2006) did not find support for temporal variability in white-footed mouse capture probabilities.

The model was implemented using the program WinBUGS version 1.4.3 via the $\mathrm{R}$ package R2WinBUGS (Sturtz et al. 2005) in the programming language R (R Core Development Team 2012). We used Uniform $(0,1)$ prior distributions for logistic parameters $\mu_{\mathrm{w}}, \mu_{\mathrm{o}}$, and $p$, Normal $(0,1000)$ prior distributions for $\beta_{\mathrm{w}}$ and $\beta_{\mathrm{o}}$, and Uniform $(0,5)$ distributions for precision parameters $\sigma_{\mathrm{a}, \mathrm{w}}^{2}, \sigma_{\mathrm{a}, \mathrm{o}}^{2}$, and $\sigma_{\mathrm{g}}^{2}$ following Kery and Schaub (2012). Prior distributions for parameters were vague or diffuse in all cases. The model was run for 500000 Gibbs steps, with the first 250000 discarded as burn-in. Convergence was assessed using the BrooksGelman-Rubin criterion, Rhat (Brooks and Gelman
1998). If a model did not converge within 500000 Gibbs steps (Rhat for any parameter $\geq 1.1$ ), it was run for 1000000 Gibbs steps, with the first 500000 discarded as burn-in. Only models for female mice, mice trapped in the three lowest acorn production years, and mice trapped in the three years following the three lowest acorn production years did not converge within 500000 Gibbs steps.

We used a simulated data set with 4800 individuals over 16 years to confirm the ability of the model to identify the coefficients of the tick effect $\beta_{\mathrm{w}}$ and $\beta_{\mathrm{o}}$. Posterior estimates for all other parameters from the model run for the full data set were used to generate simulated parameter values, excluding $\beta_{\mathrm{w}}$ and $\beta_{\mathrm{o}}$. We then set $\beta_{\mathrm{w}}$ and $\beta_{\mathrm{o}}$ at all possible combinations of $0,0.2$, and -0.2 for nine total runs. In each iteration of the simulation, the model was run for 250000 Gibbs steps, discarding the first 125000 steps as burn-in. Prior distributions were vague or diffuse in all cases. In all nine runs, the $95 \%$ credible intervals of the posterior estimates captured the set values of $\beta_{\mathrm{w}}$ and $\beta_{\mathrm{o}}$, indicating that the model is capable of accurately estimating these coefficients.

The model was run for all unique individuals $(n=$ 5587 capture histories) over 16 years, and separately for all females $(n=2573)$ and all males $(n=3014)$. We also ran selected sets of three years as separate runs to estimate $\beta_{\mathrm{w}}$ and $\beta_{\mathrm{o}}$ under particular circumstances in which survival may have been affected by other factors. We performed these analyses to determine if the effects of tick burden on survival were affected by both extrinsic and intrinsic stressors related to resource availability. These included the three years in the data set with the highest acorn density (1998, 2006, and 2010; $n=927)$, the three years with the lowest acorn density (1999, 2004, and 2007; $n=2197)$, the three years following both high- $(1995,1999$, and $2007 ; n=2015)$ and low-acorn years $(2000,2005$, and $2008 ; n=297)$, the three years with the highest population density as measured using interpolated Jolly-Seber open population model estimates for 15 August (1995, 1999, and 2007; $n=2015$; same as the three years following the highest acorn years), and the three years with the lowest population density (1996, 2000, and 2005; $n=293$ ).

Finally, we quantified relationships among several population-level variables using regression-based methods. We examined the relationship between posterior survival estimates $\left(\Phi_{y, t}\right)$ and interannual variation in acorn mast and population density using linear regression. In addition, we calculated population rate of change $(\lambda)$ between the first trapping session of larval peak $\left(t_{1}\right)$ and the last trapping session of the calendar year $\left(t_{4}\right)$ using the population growth equation $N_{t}=$ $N_{0} \lambda^{t}$, where $N_{0}$ is the initial population size, $N_{t}$ is the population size at the end of the sampling period, $t$ is the number of time steps, and $\lambda$ is the population rate of change. Population size at each sampling grid in this case was calculated using minimum number alive 


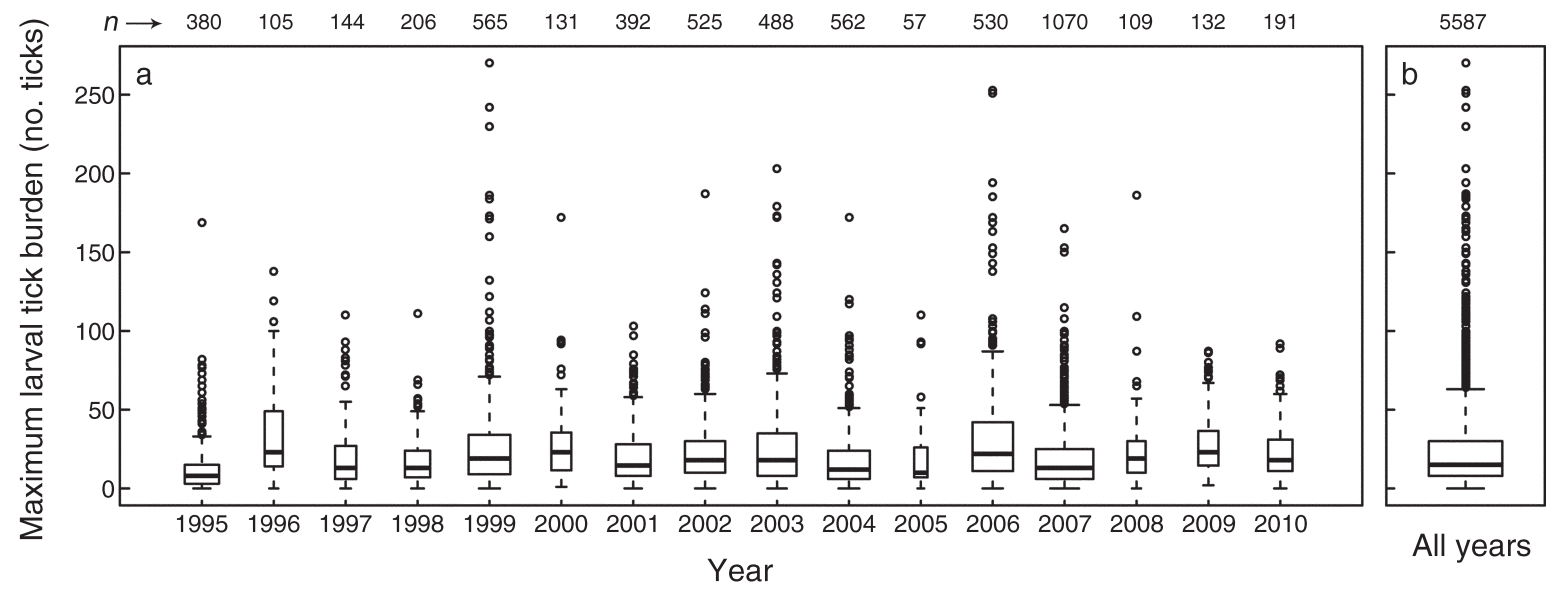

FIG. 1. Distribution of Ixodes scapularis larval tick burdens on white-footed mice (Peromyscus leucopus) (a) from 1995-2010 and (b) over the entire 16-year period. Horizontal lines are median tick burdens, and upper and lower edges of boxes are $25 \%$ and $75 \%$ quartiles, respectively. Boxes are scaled by mouse sample size, $n$. The upper whisker extends to the upper (75\%) quartile plus 1.5 times the interquartile distance (the difference between the $75 \%$ and $25 \%$ quartiles). The lower vertical line extends to the lower $(25 \%)$ qaurtile minus 1.5 times the interquartile distance. The circles represent outliers that are outside of the range of the whiskers.

(MNA), as referenced in the field methods. We then compared $\lambda$ to mean maximum tick burdens and to the index of dispersion of maximum tick burdens (variance/ mean ratio) accounting for grid identity, using analysis of covariance (ANCOVA). The negative correlation between mean maximum tick burdens and initial population size (ANCOVA; $F_{1,66}=6.181, P=0.0155$ ) prevented us from including initial population size in this analysis to avoid multicollinearity.

\section{RESULTS}

We incorporated 5587 white-footed mouse capture histories over 16 years into this analysis. The number of individual mice captured during larval peak varied annually, ranging from 57 in 2005 to 1070 in 2007 (Fig. 1). Maximum larval tick burdens (MLTB) during larval peak ranged from 0 to 270 ticks per mouse (Fig. 1, Appendix A). The overall MLTB was $22.7 \pm 23.5$ ticks/ mouse (mean \pm SD) and ranged from 12.4 (1995) to 32.6 (1996). In general, distributions of tick burdens were left skewed with a long tail (Appendix A) and the shapes of distributions varied among years (Fig. A2).

We found little evidence for an impact of larval tick burdens on white-footed mouse survival. In model runs including all individual mouse capture histories, the mean posterior estimates of $\beta_{\mathrm{w}}$ and $\beta_{\mathrm{o}}$, the coefficient for tick effects on within-season and overwinter survival, respectively, were close to zero (Table 1) and credible intervals for posterior estimates of these parameters included zero (Table 1, Fig. 2). Similarly, there was not a significant tick effect for female within-season survival, female overwinter survival, or male overwinter survival (Table 2, Fig. 2). The mean posterior estimate of $\beta_{\mathrm{w}}$ was positive for male within-season survival, and the credible interval for $\beta_{\mathrm{w}}$ in males did not contain zero (Table 2, Fig. 2), suggesting a positive association between tick burden and within-season survival in male mice.

We did not find evidence for tick effects on survival when running subsets of the data incorporating particularly high and low values in acorn production and mouse population density (Fig. 3). Credible intervals for

TABLE 1. Estimates and credible intervals (CI) for the eight state-space model parameters for all individual white-footed mice (Peromyscus leucopus; $n=5587$ mice) over 16 years.

\begin{tabular}{lcccc}
\hline \hline Parameter & Mean & SD & $2.5 \%$ CI & $97.5 \%$ CI \\
\hline$\mu_{\mathrm{w}}$ & 0.673 & 0.026 & 0.618 & 0.722 \\
$\mu_{\mathrm{o}}$ & 0.100 & 0.043 & 0.039 & 0.205 \\
$\sigma_{\mathrm{a}, \mathrm{w}}^{2}$ & 0.209 & 0.103 & 0.084 & 0.465 \\
$\sigma_{\mathrm{a}, \mathrm{o}}$ & 3.053 & 1.714 & 1.123 & 7.413 \\
$\beta_{\mathrm{w}}$ & 0.009 & 0.027 & -0.042 & 0.062 \\
$\beta_{\mathrm{o}}$ & -0.030 & 0.086 & -0.201 & 0.134 \\
$\sigma_{\mathrm{g}}^{2}$ & 0.558 & 0.146 & 0.280 & 0.859 \\
$p$ & 0.860 & 0.005 & 0.850 & 0.870 \\
\hline
\end{tabular}

Notes: Parameters are $\mu_{\mathrm{w}}$, intercept for within-season survival probability; $\mu_{\mathrm{o}}$, intercept for overwinter survival probability; $\sigma_{\mathrm{a}, \mathrm{w}}^{2}$, random year effects, within-season; $\sigma_{\mathrm{a}, \mathrm{o}}^{2}$, random year effects, overwinter; $\beta_{\mathrm{w}}$, tick effect, within-season; $\beta_{\mathrm{o}}$, tick effect, overwinter; $\sigma_{\mathrm{g}}^{2}$, individual random effects; $p=$ capture probability. Parameters $\sigma_{\mathrm{a}, \mathrm{w}}^{2}, \sigma_{\mathrm{a}, \mathrm{o}}^{2}, \beta_{\mathrm{w}}, \beta_{\mathrm{o}}$, and $\sigma_{\mathrm{g}}^{2}$ are on a logit scale. 

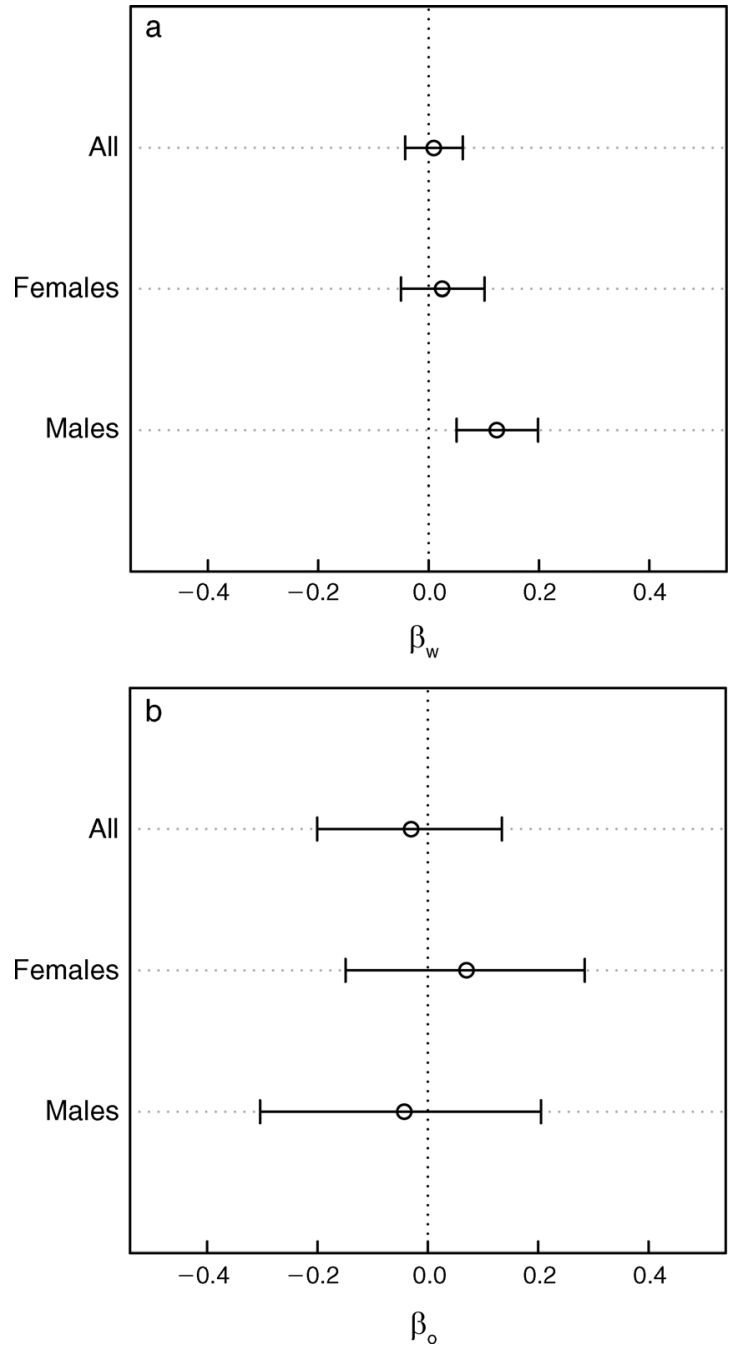

FIG. 2. Posterior estimates of (a) $\beta_{\mathrm{w}}$ and (b) $\beta_{\mathrm{o}}$, regression coefficients for the effect of larval tick burdens on within-season and overwinter survival, respectively, of white-footed mice. Both parameters were estimated separately for all individuals, for females, and for males. Error bars are 95\% credible intervals.
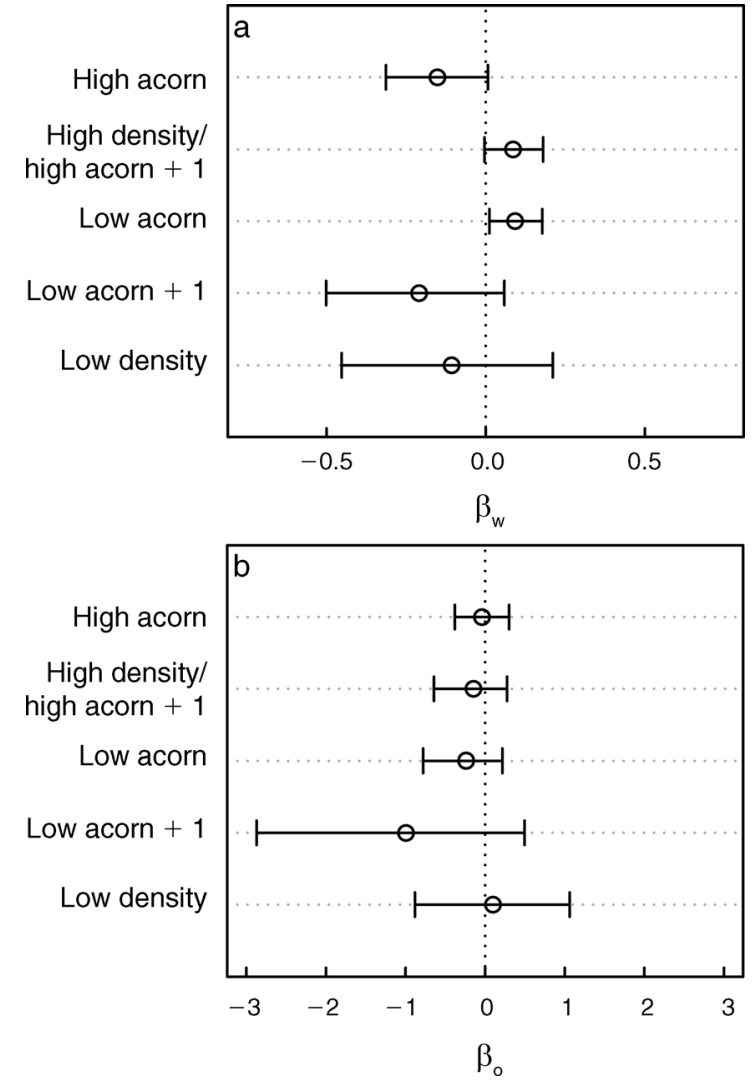

FIG. 3. Posterior estimates of (a) $\beta_{\mathrm{w}}$ and (b) $\beta_{\mathrm{o}}$, regression coefficients for the effect of larval Ixodes scapularis tick burdens on within-season and overwinter survival probability, respectively, of white-footed mice. Parameters were estimated for the three highest acorn years (high acorn), the years immediately following the three highest acorn years (high acorn +1 ), the three highest density years (high density), and the lowest of all three scenarios. The three highest density years were also the three years following the three highest acorn years in this study. See Appendix B for all parameter estimates. Error bars are 95\% credible intervals.

$\beta_{\mathrm{o}}$ contained zero in the three years with the highest and lowest acorn densities, and credible intervals for $\beta_{\mathrm{w}}$ contained zero in the three years following both the highest and lowest acorn densities (Fig. 3, Appendix B).

TABLE 2. Estimates and credible intervals for the eight model parameters for all male $(n=3014$ mice $)$ and female $(n=2573$ mice $)$ white-footed mice over 16 years.

\begin{tabular}{|c|c|c|c|c|c|c|c|c|}
\hline \multirow[b]{2}{*}{ Parameter } & \multicolumn{4}{|c|}{ Females } & \multicolumn{4}{|c|}{ Males } \\
\hline & Mean & SD & $2.5 \% \mathrm{CI}$ & $97.5 \%$ & Mean & SD & $2.5 \% \mathrm{CI}$ & $97.5 \% \mathrm{CI}$ \\
\hline$\mu_{\mathrm{w}}$ & 0.734 & 0.026 & 0.678 & 0.783 & 0.627 & 0.026 & 0.574 & 0.674 \\
\hline$\mu_{o}$ & 0.144 & 0.066 & 0.050 & 0.305 & 0.075 & 0.037 & 0.025 & 0.165 \\
\hline$\sigma_{\mathrm{a}, \mathrm{w}}^{2}$ & 0.249 & 0.128 & 0.097 & 0.571 & 0.157 & 0.089 & 0.051 & 0.388 \\
\hline$\sigma_{a 0}^{2, w}$ & 3.843 & 2.563 & 1.110 & 10.660 & 3.470 & 2.214 & 1.085 & 9.320 \\
\hline$\beta_{\mathrm{w}}^{\mathrm{a}, \mathrm{o}}$ & 0.024 & 0.039 & -0.050 & 0.101 & 0.124 & 0.038 & 0.051 & 0.198 \\
\hline$\beta_{\mathrm{o}}$ & 0.070 & 0.111 & -0.149 & 0.284 & -0.043 & 0.130 & -0.304 & 0.205 \\
\hline$\sigma_{\mathrm{g}}^{2}$ & 0.199 & 0.175 & 0.004 & 0.629 & 0.696 & 0.194 & 0.347 & 1.099 \\
\hline$p^{g}$ & 0.861 & 0.007 & 0.847 & 0.875 & 0.859 & 0.008 & 0.843 & 0.873 \\
\hline
\end{tabular}

Notes: Abbreviations for parameters follow Table 1. As above, parameters $\sigma_{\mathrm{a}, \mathrm{w}}^{2}, \sigma_{\mathrm{a}, \mathrm{o}}^{2}, \beta_{\mathrm{w}}, \beta_{\mathrm{o}}$, and $\sigma_{\mathrm{g}}^{2}$ are on a logit scale. 
Credible intervals for both $\beta_{\mathrm{w}}$ and $\beta_{\mathrm{o}}$ contained zero in the three years with the highest and lowest mouse population densities (Fig. 3, Appendix B).

Mean survival probability, including tick effects, yearly random effects, and individual random effects was $0.683 \pm 0.006$ (mean $\pm \mathrm{SD}$ ) between trapping sessions within-season and $0.121 \pm 0.009$ over winter. Mean posterior variance estimates were greatest for the interannual random effects in overwinter survival $\left(\sigma_{a, 0}^{2}\right)$, although variance in within-season survival $\left(\sigma_{\mathrm{w}, \mathrm{o}}^{2}\right)$ and individual random effects $\left(\sigma_{\mathrm{g}}^{2}\right)$ were also greater than zero (Tables 1,2). We observed a positive correlation between mean annual posterior estimates of overwinter survival probability and log-transformed acorn density (same year; $F_{1,14}=7.73$, adjusted $R^{2}=0.31, P=0.0147$ ) but no analogous relationship between within-season survival and acorn density for the previous year $\left(F_{1,14}=\right.$ 1.3 , adjusted $\left.R^{2}=0.0194, P=0.274\right)$. There was no correlation between mean annual posterior estimates of overwinter survival and log-transformed mouse density $\left(F_{1,14}=0.374\right.$, adjusted $\left.R^{2}=0.0435, P=0.551\right)$, but a positive relationship between density and within-season survival $\left(F_{1,14}=5.46\right.$, adjusted $\left.R^{2}=0.229, P=0.0348\right)$.

Finally, population rate of change within a breeding season was not reduced by heavy tick burdens on mice (Fig. 4). Mean maximum tick burdens were positively correlated with the population rate of change (ANCOVA; $F_{1,66}=8.663, P=0.00448$; Fig. 4$)$. The effect of individual trapping grids was not significant $\left(F_{5,66}=\right.$ $0.341, P=0.886)$, nor was there an interaction between mean tick burdens and grid $\left(F_{5,66}=1.638, P=0.162\right)$. The index of dispersion of maximum tick burdens (variance/mean ratio) was not correlated with the population rate of change (ANCOVA; $F_{1,66}=3.100, P$ $=0.083)$. In this analysis, the effect of individual trapping grids was also not significant $\left(F_{5,66}=1.142, P\right.$ $=0.347)$, and again we did not find a significant interaction between mean tick burdens and grid $\left(F_{5,66}\right.$ $=0.983, P=0.435)$.

\section{DisCUSSION}

We estimated the effects of larval tick burdens on within-season and overwinter mouse survival probabilities using 16 years of mark-recapture data for over 5500 individual mice. Although tick burdens sometimes reached over 200 ticks per host, we found that larval Ixodes scapularis ticks had few measurable effects on white-footed mouse survival probabilities and none that were negative. This lack of negative effects of heavy tick burdens on survival was contrary to our predictions. We would predict that high tick burdens have a negative effect on survival, given that ticks feed on mouse blood. The positive correlation between tick burdens and within-season survival probability in male mice was particularly unexpected. There are several reasons why we might not have observed the expected result.

First, heavy tick infestations in mice could be associated with behavioral patterns that may increase

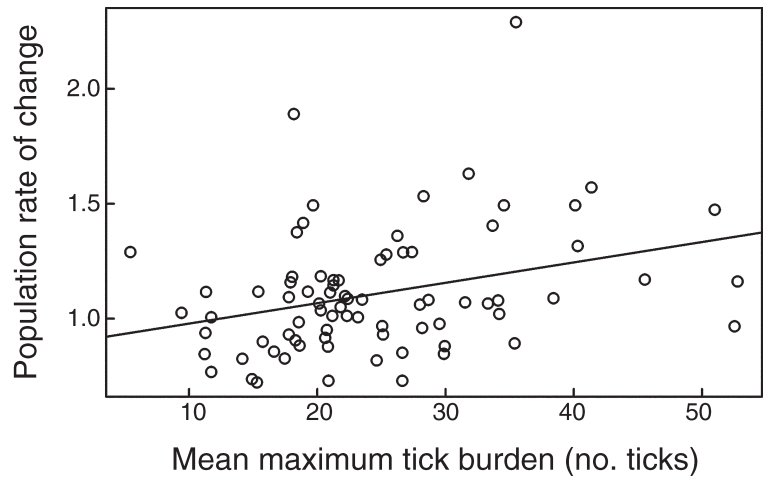

FIG. 4. Correlation between mean maximum tick burden and white-footed mouse population rate of change. Regression line is displayed as a simple linear model $\left(F_{1,76}=8.675\right.$, adjusted $R^{2}=0.09, P=0.00428$, given that there was not a significant main effect of grid in this analysis.

survival and offset health costs of parasitism. Heavily infested mice may exhibit more risk-averse behavior in response to predation. For example, flea-infested gerbils had a stronger response to the threat of fox predation than uninfested gerbils, leaving food trays at higher giving-up densities and spending less time in food trays overall (Raveh et al. 2011). This kind of avoidance behavior lowers foraging success, but it also decreases predation risk. On the other hand, studies of endoparasite burdens have shown the opposite effect on tadpoles, where parasitized individuals became more susceptible to predation (Lefcort and Blaustein 1995).

Second, heavily tick-infested mice may occupy microhabitats more conducive to both tick and mouse survival. Other models of this system have shown that large tick aggregations on individual mice are due to the bad luck of occupying a tick-rich microhabitat rather than any individual predictor (Calabrese et al. 2011) and that individuals with high larval tick burdens also have high nymphal tick burdens (Brunner and Ostfeld 2008). Heavily infested individuals may reside in microhabitats with denser vegetation, which is more conducive to tick survival (Kiffner et al. 2011) but may also provide cover from predation for mice as well. Since predation is an important cause of mortality in small mammal populations (Meserve et al. 2003, Ekerholm et al. 2004, Previtali et al. 2009), behaviors associated with tick infestation that simultaneously decrease predation risk may balance out negative effects of tick feeding on mouse survival.

Potentially, several other individual-level traits might underlie both survival probability and the tendency of mice to accumulate ticks, disrupting a direct causal relationship. For instance, the biggest individuals in the population might simultaneously be most heavily parasitized and most likely to survive (Perkins et al. 2003, Devevey and Brisson 2012). Larger animals have been shown to have higher tick burdens in some systems (Kiffner et al. 2011) and the effect of body size has been 
proposed to drive male-biased differences in tick burdens in other small mammal species (Harrison et al. 2010), but other studies have not found strong correlations between ectoparasite loads and body size (Perez-Orella and Schulte-Hostedde 2005). Previous work with an 11-year subset of the data in this study did not find sex, age, or body mass to explain aggregation patterns of tick burdens (Brunner and Ostfeld 2008). Another important trait could be home range size. Individuals with larger home ranges (such individuals may be dominant and thus more likely to survive) may simply encounter more ticks. Home range size was not found to be related to larval tick burdens in another population of Peromyscus leucopus (Devevey and Brisson 2012), but other studies have found increased tick burdens with higher space use or exploratory behavior in other small mammal species (Boyer et al. 2010). Finally, effects of tick burdens on survival may be nonlinear, perhaps due to the cost of resistance in individuals with low parasite loads (Stjernman et al. 2008). We note that larval and nymphal tick burdens are positively correlated in this system (Brunner and Ostfeld 2008). If nymphs or nymph-transmitted pathogens reduce mouse survival or population growth rates, then any correlated larval burden would also be associated with reduced mouse survival or population growth. Instead, the lack of negative effects of larval burdens suggests that effects of larvae are not masked by any potential negative effects of nymphs or nymphtransmitted pathogens.

In addition, there is a known trade-off between reproductive effort and survival in many animal species (Stearns 1992). It may be that any negative effects of ticks on mouse health are manifested in decreased reproductive effort, which can enhance survival. For instance, high bot fly parasitism was associated with reduced secondary reproductive success and increased survival in white-footed mice (Burns et al. 2005). Decreased reproductive success is a known consequence of ectoparasitism in some mammal systems (Neuhaus 2003, Hillegass et al. 2010) but not all (Gooderham and Schulte-Hostedde 2011). Measuring reproductive output was outside of the scope of this study; however, if heavy tick burdens reduce reproductive effort substantially without affecting survival, we would expect to find a negative correlation between maximum tick burdens and population rate of change. Our finding of a positive correlation between mean maximum tick burdens and population rate of change appears to reduce the likelihood that tick parasitism was reducing reproductive output in our populations.

Although mouse population density and acorn production can be correlated with survival probabilities, we did not find differences in the effect of ticks on survival in high-population vs. low-population years or in high-acorn vs. low-acorn years (Fig. 3). The weak (and occasionally positive, in the case of male mice) effects of ticks on mouse survival were robust over large ranges of variation in extrinsic (food supply) and intrinsic (population density) factors. These observations contrasted with our expectation that, should a negative effect of ticks on mice occur, it would be stronger during stressful periods, such as years of high population density or low food supply.

The positive correlation between mean maximum tick burdens and $\lambda$ (the population rate of change) and the lack of relationship between the variance/mean ratio of tick burdens and $\lambda$ support the conclusion that high tick burdens have minimal to no cost to mice at the population level. Observed higher tick burdens when initial population size is low (see Methods), perhaps indicative of tick crowding on scarce hosts, could partially explain the positive correlation between $\lambda$ and mean tick burden. In addition, this result suggests that high mean tick burdens are not increasing survival by reducing reproductive effort, because decreased reproductive effort should lower $\lambda$. The absence of a clear negative relationship between tick burdens and population rate of change suggests that that mouse populations are unlikely to be regulated by these ectoparasites, though further study is needed.

Our observation that ticks do not decrease mouse survival probability or population growth rate has implications for the dynamics of blacklegged ticks and the pathogens they transmit. Prior research has demonstrated a strong, positive effect of mouse abundance on the subsequent abundance of tick nymphs (Ostfeld et al. 2001, 2006, Ostfeld 2011), the stage responsible for maintaining the enzootic cycle of tick-borne pathogens. In contrast to the role of mice in regulating tick abundance, we find no reciprocal regulatory effect of ticks on mice. The absence of this regulatory pathway increases the likelihood of destabilizing positive feedback loops. In theoretical models, this kind of mortality tolerance has positive effects on parasite fitness (Best et al. 2008). The apparent indifference of white-footed mice to variable tick burdens could contribute to their importance as reservoir hosts in the transmission of multiple tick-borne pathogens.

\section{ACKNOWLEDGMENTS}

We thank Kelly Oggenfuss and many years of mouse-mast field crews for collecting the data used in this study, along with Charlie Canham and Jesse Brunner for assistance in model implementation and data preparation, respectively. Felicia Keesing provided useful comments on this study and manuscript. This research was funded by the United States National Science Foundation, most recently grant DEB 0949702 to R. S. Ostfeld and C. D. Canham.

\section{Literature Cited}

Anderson, R. M., and R. M. May. 1978. Regulation and stability of host-parasite population interactions: I. Regulatory processes. Journal of Animal Ecology 47:219-247.

Antoniazzi, L. R., D. E. Manzoli, D. Rohrmann, M. J. Saravia, L. Silvestri, and P. M. Beldomenico. 2011. Climate variability affects the impact of parasitic flies on Argentinean forest birds. Journal of Zoology 283:126-134. 
Best, A., A. White, and M. Boots. 2008. Maintenance of host variation in tolerance to pathogens and parasites. Proceedings of the National Academy of Sciences USA 105:2078620791.

Boyer, N., D. Reale, J. Marmet, B. Pisanu, and J. L. Chapuis. 2010. Personality, space use, and tick load in an introduced population of Siberian chipmunks Tamias sibiricus. Journal of Animal Ecology 79:538-547.

Brooks, S., and A. Gelman. 1998. General methods for monitoring convergence of iterative simulations. Journal of Computational and Graphical Statistics 7:434-455.

Brown, C. R., K. R. Brazeal, S. A. Strickler, and M. B. Brown. 2006. Feather mites are positively associated with daily survival in cliff swallows. Canadian Journal of Zoology 84: 1307-1314.

Brown, C. R., and M. B. Brown. 1992. Ectoparasitism as a cause of natal dispersal in cliff swallows. Ecology 73:17181723.

Brown, C. R., and M. B. Brown. 2004. Group size and ectoparasitism affect daily survival probability in a colonial bird. Behavioral Ecology and Sociobiology 56:498-511.

Brown, C. R., M. B. Brown, and B. Rannala. 1995. Ectoparasites reduce long-term survival of their avian host. Proceedings of the Royal Society B 262:313-319.

Brunner, J. L., and R. S. Ostfeld. 2008. Multiple causes of variable tick burdens on small-mammal hosts. Ecology 89: 2259-2272.

Burns, C. E., B. J. Goodwin, and R. S. Ostfeld. 2005. A prescription for longer life? Bot fly parasitism of the whitefooted mouse. Ecology 86:753-761.

Calabrese, J. M., J. L. Brunner, and R. S. Ostfeld. 2011. Partitioning the aggregation of parasites on hosts into intrinsic and extrinsic components via an extended Poissongamma mixture model. PLoS ONE 6:e29215.

Cardon, M., G. Loot, G. Grenouillet, and S. Blanchet. 2011. Host characteristics and environmental factors differentially drive the burden and pathogenicity of an ectoparasite: a multilevel causal analysis. Journal of Animal Ecology 80: 657-667.

Christe, P., O. Glaizot, G. Evanno, N. Bruyndonckx, G. Devevey, G. Yannic, P. Patthey, A. Maeder, P. Vogel, and R. Arlettaz. 2007. Host sex and ectoparasites choice: preference for, and higher survival on female hosts. Journal of Animal Ecology 76:703-710

Civitello, D. J., E. Rynkiewicz, and K. Clay. 2010. Metaanalysis of coinfections in ticks. Israel Journal of Ecology and Evolution 56:417-431.

Clark, J. S., G. A. Ferraz, N. Oguge, H. Hays, and J. DiCostanzo. 2005. Hierarchical Bayes for structured, variable populations: from recapture data to life-history prediction. Ecology 86:2232-2244.

Clayton, D. H., and D. M. Tompkins. 1995. Comparative effects of mites and lice on the reproductive success of rock doves (Columba livia). Parasitology 110:195-206.

Cormack, R. M. 1964. Estimates of survival from the sightings of marked animals. Biometrika 51:429-438.

Devevey, G., and D. Brisson. 2012. The effect of spatial heterogeneity on the aggregation of ticks on white-footed mice. Parasitology 139:915-925.

Devevey, G., and P. Christe. 2009. Flea infestation reduces the life span of the common vole. Parasitology 136:1351-1355.

Ekerholm, P., L. Oksanen, T. Oksanen, and M. Schneider. 2004. The impact of short-term predator removal on vole dynamics in an arctic-alpine landscape. Oikos 106:457-468.

Fitze, P. S., J. Clobert, and H. Richner. 2004a. Long-term lifehistory consequences of ectoparasite-modulated growth and development. Ecology 85:2018-2026.

Fitze, P. S., B. Tschirren, and H. Richner. 2004b. Life history and fitness consequences of ectoparasites. Journal of Animal Ecology 73:216-226.
Gauthier-Clerc, M., S. Mangin, C. Le Bohec, and J. P. Gendner. 2003. Comparison of behaviour, body mass, haematocrit level, site fidelity, and survival between infested and non-infested king penguin Aptenodytes patagonicus by ticks Ixodes uriae. Polar Biology 26:379-382.

Gimenez, O., V. Rossi, R. Choquet, C. Dehais, B. Doris, H. Varella, J. P. Vila, and R. Pradel. 2007. State-space modelling of data on marked individuals. Ecological Modelling 206: $431-438$.

Gooderham, K., and A. Schulte-Hostedde. 2011. Macroparasitism influences reproductive success in red squirrels (Tamiasciurus hudsonicus). Behavioral Ecology 22:1195-1200.

Gorrell, J. C., and A. I. Schulte-Hostedde. 2008. Patterns of parasitism and body size in red squirrels (Tamiasciurus hudsonicus). Canadian Journal of Zoology 86:99-107.

Hammond, E. L., and R. G. Anthony. 2006. Mark-recapture estimates of population parameters for selected species of small mammals. Journal of Mammalogy 87:618-627.

Harrison, A., M. Scantlebury, and W. I. Montgomery. 2010. Body mass and sex-biased parasitism in wood mice Apodemus sylvaticus. Oikos 119:1099-1104.

Hawlena, H., Z. Abramsky, and B. R. Krasnov. $2006 a$ Ectoparasites and age-dependent survival in a desert rodent. Oecologia 148:30-39.

Hawlena, H., I. S. Khokhlova, Z. Abramsky, and B. R. Krasnov. 2006b. Age, intensity of infestation by flea parasites, and body mass loss in a rodent host. Parasitology 133:187-193.

Hersh, M. H., M. Tibbetts, M. Strauss, R. S. Ostfeld, and F. Keesing. 2012. Quantifying reservoir competence of wildlife host species for Babesia microti. Emerging Infectious Diseases 18:1951-1957.

Heylen, D. J. A., and E. Matthysen. 2008. Effect of tick parasitism on the health status of a passerine bird Functional Ecology 22:1099-1107.

Hillegass, M. A., J. M. Waterman, and J. D. Roth. 2010 Parasite removal increases reproductive success in a social African ground squirrel. Behavioral Ecology 21:696-700.

Jolly, G. M. 1965. Explicit estimates from capture-recapture data with both death and immigration-stochastic model. Biometrika 52:225-247.

Jones, C. G., R. S. Ostfeld, M. P. Richard, E. M. Schauber, and J. O. Wolff. 1998. Chain reactions linking acorns to gypsy moth outbreaks and Lyme disease risk. Science 279:10231026.

Keesing, F., J. Brunner, S. Duerr, M. Killilea, K. LoGiudice, K. Schmidt, H. Vuong, and R. S. Ostfeld. 2009. Hosts as ecological traps for the vector of Lyme disease. Proceedings of the Royal Society B 276:3911-3919.

Keesing, F., M. H. Hersh, M. Tibbetts, D. J. McHenry, S. Duerr, J. Brunner, M. Killilea, K. LoGiudice, K. A. Schmidt, and R. S. Ostfeld. 2012. Identifying reservoir hosts of Anaplasma phagocytophilum. Emerging Infectious Diseases 18:2013-2016.

Kery, M., and M. Schaub. 2012. Bayesian population analysis using WinBUGS. Elsevier, Waltham, Massachusetts, USA.

Kiffner, C., T. Vor, P. Hagedorn, M. Niedrig, and F. Ruhe. 2011. Factors affecting patterns of tick parasitism on forest rodents in tick-borne encephalitis risk areas, Germany. Parasitology Research 108:323-335.

Krasnov, B. R., S. Morand, H. Hawlena, I. S. Khokhlova, and G. I. Shenbrot. 2005. Sex-biased parasitism, seasonality, and sexual size dimorphism in desert rodents. Oecologia 146:209217

Krkosek, M., J. S. Ford, A. Morton, S. Lele, R. A. Myers, and M. A. Lewis. 2007. Declining wild salmon populations in relation to parasites from farm salmon. Science 318:17721775.

Lee, P. L. M., and D. H. Clayton. 1995. Population biology of swift (Apus apus) ectoparasites in relation to host reproductive success. Ecological Entomology 20:43-50. 
Lefcort, H., and A. R. Blaustein. 1995. Disease, predator avoidance, and vulnerability to predation in tadpoles. Oikos 74:469-474.

LoGiudice, K., R. S. Ostfeld, K. A. Schmidt, and F. Keesing. 2003. The ecology of infectious disease: effects of host diversity and community composition on Lyme disease risk. Proceedings of the National Academy of Sciences USA 100: $567-571$.

Lourenco, S. I., and J. M. Palmeirim. 2007. Can mite parasitism affect the condition of bat hosts? Implications for the social structure of colonial bats. Journal of Zoology 273:161-168.

Merino, S., and J. Potti. 1995. Mites and blowflies decrease growth and survival in nestling pied flycatchers. Oikos 73:95103.

Meserve, P. L., D. A. Kelt, W. B. Milstead, and J. R. Gutierrez. 2003. Thirteen years of shifting top-down and bottom-up control. BioScience 53:633-646.

Moller, A. P. 1993. Ectoparasites increase the cost of reproduction in their hosts. Journal of Animal Ecology 62: 309-322.

Monticelli, D., J. A. Ramos, J. E. Hines, J. D. Nichols, and J. A. Spendelow. 2008. Juvenile survival in a tropical population of roseate terns: interannual variation and effect of tick parasitism. Marine Ecology Progress Series 365:277287.

Neuhaus, P. 2003. Parasite removal and its impact on litter size and body condition in Columbian ground squirrels (Spermophilus columbianus). Proceedings of the Royal Society B 270: S213-S215.

Ostfeld, R. S. 2011. Lyme disease: the ecology of a complex system. Oxford University Press, New York, New York, USA.

Ostfeld, R. S., C. D. Canham, K. Oggenfuss, R. J. Winchcombe, and F. Keesing. 2006. Climate, deer, rodents, and acorns as determinants of variation in Lyme disease risk. PLoS Biology 4:1058-1068.

Ostfeld, R. S., C. G. Jones, and J. O. Wolff. 1996. Of mice and mast. BioScience 46:323-330.

Ostfeld, R. S., R. H. Manson, and C. D. Canham. 1997. Effects of rodents on survival of tree seeds and seedlings invading old fields. Ecology 78:1531-1542.

Ostfeld, R. S., E. M. Schauber, C. D. Canham, F. Keesing, C. G. Jones, and J. O. Wolff. 2001. Effects of acorn production and mouse abundance on abundance and Borrelia burgdorferi infection prevalence of nymphal Ixodes scapularis ticks. Vector-Borne and Zoonotic Diseases 1:5563.

Perez-Orella, C., and A. I. Schulte-Hostedde. 2005. Effects of sex and body size on ectoparasite loads in the northern flying squirrel (Glaucomys sabrinus). Canadian Journal of Zoology 83:1381-1385.

Perkins, S. E., I. M. Cattadori, V. Tagliapietra, A. P. Rizzoli, and P. J. Hudson. 2003. Empirical evidence for key hosts in persistence of a tick-borne disease. International Journal for Parasitology 33:909-917.

Previtali, M. A., M. Lima, P. L. Meserve, D. A. Kelt, and J. R. Gutierrez. 2009. Population dynamics of two sympatric rodents in a variable environment: rainfall, resource availability, and predation. Ecology 90:1996-2006.

R Development Core Team. 2012. R: a language and environment for statistical computing. R Foundation for Statistical Computing, Vienna, Austria. www.r-project.org

Ramos, J. A., J. Bowler, L. Davis, S. Venis, J. Quinn, and C. Middleton. 2001. Activity patterns and effect of ticks on growth and survival of tropical Roseate Tern nestlings. Auk 118:709-716.

Raveh, A., B. P. Kotler, Z. Abramsky, and B. R. Krasnov. 2011. Driven to distraction: detecting the hidden costs of flea parasitism through foraging behaviour in gerbils. Ecology Letters 14:47-51.

Royle, J. A. 2008. Modeling individual effects in the CormackJolly-Seber model: a state-space formulation. Biometrics 64 : 364-370.

Schmidt, K. A., J. R. Goheen, R. Naumann, R. S. Ostfeld, E. M. Schauber, and A. Berkowitz. 2001. Experimental removal of strong and weak predators: mice and chipmunks preying on songbird nests. Ecology 82:2927-2936.

Seber, G. A. F. 1965. A note on the multiple-recapture census. Biometrika 52:249-259.

Stearns, S. C. 1992. The evolution of life histories. Oxford University Press, New York, New York, USA.

Stjernman, M., L. Raberg, and J.-A. Nilsson. 2008. Maximum host survival at intermediate parasite infection intensities. PLoS ONE 3:e2463.

Sturtz, S., U. Ligges, and A. Gelman. 2005. R2WinBUGS: a package for running WinBUGS from R. Journal of Statistical Software 12:1-16.

Turchin, P. 2003. Complex population dynamics: a theoretical/ empirical synthesis. Princeton University Press, Princeton, New Jersey, USA.

\section{Supplemental Material}

\section{Appendix A}

Distributions of maximum Ixodes scapularis larval tick burdens on white-footed mice (Peromyscus leucopus) captured during larval peak from 1992-2010 for all years combined and each year separately (Ecological Archives XXXXX).

\section{Appendix B}

Parameter estimates for survival of white-footed mice in sets of three years representing particularly high or low levels of (1) acorn density in the current year, (2) acorn density in the previous year, and (3) mouse population density (Ecological Archives XXXXX) 
Queries for ecol-95-04-29

This manuscript/text has been typeset from the submitted material. Please check this proof carefully to make sure there have been no font conversion errors or inadvertent formatting errors. Allen Press. 